\title{
Research on the Dynamic Mechanism of Enterprise Synergy Innovation: A Literature Review
}

\author{
He Zhenqian ${ }^{1} \&$ Xu Ming ${ }^{1}$ \\ ${ }^{1}$ Glorious Sun School of Business and Management, Donghua University, P.R. China \\ Correspondence: He Zhenqian, Glorious Sun School of Business and Management, Donghua University 200051, \\ P.R. China. Tel: 86-138-1783-4155. E-mail: Zhenqian_he@sina.com
}

Received: November 14, 2016

Accepted: December 5, 2016

Online Published: December 20, 2016

doi:10.5539/ass.v13n1p141

URL: http://dx.doi.org/10.5539/ass.v13n1p141

\begin{abstract}
Innovation is the guarantee of enterprises to win in the market, while the synergy innovation is an effective way of enterprise innovation. Based on the synergy innovation concepts and theoretical analysis, this paper studies abroad enterprise synergy innovation background and the way of realization. It theoretically sums up the synergy innovation dynamic mechanism from both the internal dynamic mechanism and the external dynamic mechanism, and summarizes the role of the synergy innovation in practice. It also discusses what can be learned from the foreign experience.
\end{abstract}

Keywords: synergy innovation; dynamic mechanism; driving force analysis; industrial alliance

\section{Introduction}

In the knowledge economy era, enterprise is the principal part of the innovation, synergy innovation is one effective way to help the enterprise realize the outputs maximization with limited inputs. The synergy innovation is not limited to new product, new service, but with the innovation on BPM and business model. The enterprises are now emphasizing on the management concept and the organization structure optimization to keep high level creativity and innovation spirit ${ }^{[1]}$.

The success depends on the synergy of multi-elements. The synergy might consist of the internal elements as the enterprise culture, the management, technology, it also might be the multi-agents' synergy between the enterprise and the external elements as the external enterprise, the university, the scientific institute and the Government, etc. ${ }^{[2]}$ This paper studies on the literatures of synergy innovation related, setting up the synergy innovation definition, classifying the internal and external mechanism on the synergy innovation and pointing out the research route on the dynamic mechanism of enterprise synergy innovation.

\section{Literature Studied}

\subsection{Synergy Innovation Definition}

The meaning of the synergy innovation is very complicated. On one hand, it is owning to the diversity of the synergy innovation forms, on the other hand, it is also with the complexity of the synergy innovation theory. Domestic and the foreign scholars have put forward relative definitions. The earliest definition was put forward by Professor Gloor ${ }^{[3]}$ from MIT Sloan Center, "It's the networking group vision from the self-motivated group members, they exchange thoughts, information and work through internet crossing countries' collaboration to achieve the common goal". After that, there're researchers put forward the horizontal and vertical synergy innovation concepts with the enterprises as the innovation subject. The horizontal synergy innovation is the cooperation among the competitors, the research institutes and the universities, the vertical synergy innovation is the cooperation between the suppliers and the clients. Some researchers think the enterprises, the universities and the researchers' synergy innovation is one input and output system in the enterprises, the universities and researchers' trinity mode, the researchers realize the synergy through communication and exchange with the input of human, financial and material resources to get the innovation performance output. Chen Jing defines the synergy manufacturing is the basis of the synergy innovation, the synergy innovation is the innovation among the enterprises, the government, the knowledge production organizations, the intermediary organizations and the clients to achieve the innovation organization mode with breakthrough technology innovation, knowledge value-added as the core and long span integration ${ }^{[1]}$. There're also definitions of narrow sense and broad sense, 
the definition from narrow sense is two or two above enterprises carry out technology innovation or product research to form the synergy cooperation and the definition from broad sense is two or two above organizations participate with knowledge sharing and technology transferrin to form cooperation relation.

The success of synergy innovation is determined by the applicable conditions and the implementing organization with these applicable conditions. The synergy innovation provides the joining force with multi-agents' cooperation to achieve the higher income and lower risk through important innovation activities.

Summarizing the research on the synergy innovation home and abroad, this paper makes the synergy innovation definition as:

Table 1. Synergy Innovation Definitions from the Researchers home and abroad

\begin{tabular}{|c|c|c|}
\hline Researcher & Year & Major Point \\
\hline $\begin{array}{l}\text { Peter Gloor } \\
{[3]}\end{array}$ & 2005 & $\begin{array}{l}\text { hieving the common goal with the thought and technology communication through } \\
\text { twork platform. }\end{array}$ \\
\hline $\begin{array}{l}\text { Persaud A } \\
{[4]}\end{array}$ & 2005 & $\begin{array}{l}\text { nergy Innovation is the synergetic process that several participants cooperate to achieve } \\
\text { novation performance through the research and the development cooperation. }\end{array}$ \\
\hline$\underset{[5]}{\text { Ketchen D. }}$ & 2007 & $\begin{array}{l}\text { ynergy Innovation is the co-creation with the crossing organizations through the thought, } \\
\text { nowledge and domain expertise exchange and communication to maintain the } \\
\text { gganization sustainable innovation. }\end{array}$ \\
\hline Serran F. ${ }^{[6]}$ & 2007 & $\begin{array}{l}\text { Synergy Innovation is one complicated interactive system of the crossing synthesis with } \\
\text { knowledge, technology, information and resource. }\end{array}$ \\
\hline StefanS $S^{[7]}$ & 2009 & $\begin{array}{l}\text { Synergy Innovation is to improve the organization's innovation performance with the } \\
\text { effective response to the environment changes. }\end{array}$ \\
\hline Chen Jing $^{[1]}$ & 2012 & $\begin{array}{l}\text { Synergy innovation is the innovation among the enterprises, the Government, the } \\
\text { knowledge production organizations, the intermediary organizations and the clients to } \\
\text { achieve the innovation organization mode with breakthrough technology innovation, } \\
\text { knowledge value-added as the core and long span integration. }\end{array}$ \\
\hline $\begin{array}{l}\text { Zhang } \\
\text { Zaiqun }^{[9]}\end{array}$ & 2013 & $\begin{array}{l}\text { Synergy Innovations from narrow sense and broad sense, the definition from narrow sense } \\
\text { is two or two above enterprises carry out technology innovation or product research to } \\
\text { form the synergy cooperation and the definition from broad sense is two or two above } \\
\text { organizations participate with knowledge sharing and technology transferrin to form } \\
\text { cooperation relation. }\end{array}$ \\
\hline $\begin{array}{l}\text { Tao } \\
\text { Chun }{ }^{[26]}\end{array}$ & 2013 & $\begin{array}{l}\text { Synergy Innovation is that the multi agents cooperate and innovate synchronously with } \\
\text { consensus to the important and complicated innovation activity based on the mutual trust } \\
\text { and knowledge accumulated. Mutual trust and knowledge accumulated is the base, } \\
\text { consensus is the vision and cooperate and innovate synchronously is method. }\end{array}$ \\
\hline Chen $\mathrm{Bo}^{[8]}$ & 2014 & $\begin{array}{l}\text { Synergy Innovation is to guide and arrange the mechanism with state will to push the } \\
\text { universities, research institutes and enterprises to play different roles, coordinate resource, } \\
\text { realize complementary strengths and facilitate the technology roll out and } \\
\text { industrialization. }\end{array}$ \\
\hline
\end{tabular}

\subsection{Type of Synergy Innovation}

Type of the synergy innovation includes the enterprises, the universities and the researchers' synergy innovation, the industrial cluster innovation, the production chain synergy innovation, the enterprise synergy innovation networking organization, etc. The enterprises, the universities and the researchers' synergy innovation is the crossing organizations' and the crossing departments' innovation activity, the research on the enterprises, the universities and the researchers' synergy innovation in China starts from 1990s, the theorists recognize the importance of the organization the enterprises, the universities and the researchers' cooperation. The enterprises, the universities and the researchers' synergy innovation reflects the systematic mindset from the closed innovation to the open innovation ${ }^{[10]}$. Some researchers think the innovation of the enterprises in the supply 
chain should be on mutual trust basis. The enterprise oriented production chain innovation is that the enterprises carry out value creation activities through positioning and relationship changes in the value chain. Industrial cluster is to provide continuous support to the enterprises, universities and researchers' synergy innovation ${ }^{[8]}$. The form and perfection of the regional collaborative innovation networking forms the organization foundation for the enterprises, the universities and the researchers' synergy innovation. The synergy innovation networking organization not only has the specific objectives of the traditional enterprises, but also introduces the flexible marketing mechanism. The synergy innovation networking organization emphasizes on the collaboration and multi-winning targets with networking organization elements on the society, economic and technological platform ${ }^{[9]}$.

\section{Driving Forces Analysis on Synergy Innovation}

From closed innovation theory to open innovation theory, then to the synergy innovation put forward by the theorists these years. The more comprehensive is that the researchers make on the innovation type. The more significant is the dynamic mindset on innovation. The driving forces analysis is the necessary research content to intensify the synergy innovation research. This paper studies the elements on the driving forces of synergy innovation and the driving forces mechanism on synergy innovation is one dynamic and developing mode. We do the research on the classification of the synergy innovation. The driving forces on synergy innovation are classified into three groups as the enterprise boundary, the source of driving forces and the driving force attributes.

\subsection{Driving Forces Analysis on Enterprise Boundary}

The driving forces on the whole synergy innovation can be classified as the enterprise internal driving forces and the enterprise external driving forces based on the basis that the driving forces exist inside or outside of the enterprise.

\subsubsection{Enterprise Internal Driving Forces Analysis}

With the changing of the knowledge production mode, the technology complexity and merge, the uncertainty of the innovation has been intensifying in the past years. Key innovation activities depend on the communication and cooperation among multi-disciplines and multi-domains. The enterprises innovation capability has been challenged increasingly. Some successful enterprises have been forming synergy innovation network among the enterprises, the universities and the research institutes, the government and the intermediary organizations through the contractual relationship, the cooperative networking and the society relationship to improve the success probability, decrease the risk cost and occupy the market more efficiently.

The successful enterprises put more emphasis on the synergy innovation on the key projects excluding the competitors outside the collaborative network to stop the competitors' imitation and surpassing. The competitors can imitate one specific ability and innovation, but it's difficult to imitate the synergy innovation organization based on the multi-agents. It's one effective way to participate in the synergy innovation networking to support the surpassing. In the future, it will be difficult for the enterprises to complete the complicated innovation tasks on their own, but with the synergy innovation to play an increasingly important role.

Joseph A Schumpeter ${ }^{[11]}$ puts forward the innovation driving force firstly, he thought the innovation motive power comes from the excess profit pursuit and the entrepreneurship. Lawson ${ }^{[14]}$ brought up innovation ability concept and he mentioned that the outstanding enterprises invest and foster the innovation management ability and the innovation ability improvement include the enterprise elements as the vision and strategy, capability base, witty to change, creativity and the mindset management, the organization structure and the system, the culture, the climate and the management technology. It is to apply innovation on the new product, service and process through the effective implementation process. Eesley ${ }^{[18]}$ thought that heterogeneity of the team can enhance the enterprise innovation. Weigelt ${ }^{[16]}$ mentioned that organization structure can influence internal knowledge flow, knowledge creation and trading cost, and then strengthen the synergy innovation. Alexander and Knippenberg ${ }^{[17]}$ puts forward the point that excellent organization incentive can enhance the innovation. Shin ${ }^{[15]}$ found that the high-level differentiation and the synergy among different departments can be good pre-conditions to high performance, the absence of the members' differentiation always leads to the internal competition in the similar positions.

Domestic researchers think that the essence of enterprises on revenue pursuits and entrepreneur spirit enhance the enterprises' innovation ${ }^{[12]}$. Xiang Gang and Wang Yingluo mentioned that the motive power for enterprise sustainable innovation should come from inside, not outside of the enterprise. The basic motive power is from the sustainable improvement on the enterprise revenue and the development on enterprise size ${ }^{[13]}$. The basic 
driving force results in the entrepreneurs' mindset on the sustainable innovation and the sustainable innovation spirit, the material interest motivation, the enterprise innovation culture and the teamwork spirit. Li Baizhou and Dong Yuanyuan ${ }^{[12]}$ also thought that the enterprise's pursuits on the benefit are the core driving forces to the original innovation and is the basic original power to push the enterprise to the innovation, the entrepreneur spirit is the strong impetus to the enterprise innovation development. The entrepreneur sustainable innovation mindset and the spirit are the most important core element in the internal driving forces. There're also researchers mentioned that the cooperation between different types of employees can enhance the enterprise synergy innovation. They thought the synergy innovation among enterprise members covers the synergy innovation between the employees and the departments. The cooperation among marketing and sales, manufacturing and production, research and development can improve the innovation success significantly.

Theorists have also been studying on the enterprise resource, capital, information, technology and talent beside the research on the enterprise benefit pursuit and the entrepreneur spirit. The study above supports the enterprises to seek the synergy innovation development and the improvement on the enterprise operation management.

\subsubsection{Enterprise External Driving Forces Analysis}

With the background of the globalization and informatization, the success on the significant innovation activity is the society collaboration process. Facing the more and fiercer international competition, some developed countries hope to improve the enterprise and industry innovation competition advantages through the improvement on the science and technology, strengthen the marketing vitality and driving force, lower the risk cost on the major projects. The Government need to set the regulation for the enterprise synergy innovation, encourage the enterprises to cooperate with other organizations, lower the risk, improve the return and enhance the product innovation and the process innovation.

Organization alliance provides the platform for the synergy innovation, the stakeholders realize the resource complementary on the knowledge and information and then set the foundation for the synergy innovation. The innovation plays important role in the enterprise competition in the knowledge society. At the same time, the organization alliance can provide the impetus to the innovation. Ayunso ${ }^{[19]}$ mentioned that the stakeholders can take advantage of the organization resource to enhance the mutual communication, transferring, sharing and feedback to all the parties. Peter ${ }^{[20]}$ put forward that the synergy innovation can promote the knowledge sharing and facilitate the enterprise innovation. The increase of the partners also adds the risk related. Hence, the effective synergy innovation is to form the network with the resource complementary. Love ${ }^{[22]}$ pointed out that learning effects can result from all the exploring external connection and also enhance the enterprises to produce more innovation outcomes. This is one exchange and information processing process when opening the external knowledge source through the searching activity and connecting the external cooperators in the new product development. Eesley ${ }^{[18]}$ thought that the synergy innovation between different foundering teams can realize the excellent performance when pursuing the innovation strategy.

The synergy innovation can enhance the knowledge sharing, accelerate the production of the enterprise innovation. At the same time, the increase of the partners can create related risk. Hence, the effective synergetic network should be the network complementary with the enterprise's resource. The network development depends on the government provide excellent environment to normalize the market to maintain the sustainable synergy innovation. Synergy innovation needs the information flow and knowledge flow to move freely like the air. In reality, there're Information asymmetry, intelligence property barriers and restriction on talent flow restricting the enterprise synergy innovation. The enterprises need the government to provide the external environment adapting the synergy innovation, lower the innovation risk cost and increase the innovation success probability. There're more highly competent talents and frequent communication on the affluent innovation knowledge sources and the basic elements with successful synergy innovation in some of the developed countries ${ }^{[24]}$.

Domestic theorists have been studying the synergy innovation focusing on the resources complementary, mutual trust, cooperation and collaboration among different multi-agents to achieve win-win and all-win. There're major influencing factors on the development of synergy innovation as the society economy, the culture, the science and technology, the ecosystem and the government policy with the changes of the science, the marketing demand and the marketing mechanism. Zhang Weifeng ${ }^{[23]}$ thought the enterprise can absorb and develop new knowledge from external environment not only to break the rigid phenomenon on its own knowledge development, but also acquire new knowledge to realize and assure the innovation success well. Fang Taisheng ${ }^{[21]}$ put forward the enterprise applying the competitive, cooperative and interactive collaborative mode to enhance the fostering of the sustainable innovation dynamic driving mechanism through the value solidification with internal innovation 
elements connection in the industrial cluster. The cooperators in the synergy innovation interpenetrate through resource dependence and value alliance to form the innovation network in the dynamic ecosystem. The network can develop by itself to realize the competitive advantage upgrading in the industrial cluster. The researcher considered that the driving elements in the enterprise synergy innovation covering the demand to develop the innovation competitive advantage, resource complementary, strategy development and organization learning. With the booming development of the knowledge and networking economy, information networking technology and the diversity and individualization of the customer requirements enhance the enterprise synergy innovation development. Some thought that the government's guidance and promotion is the important impetus to the collaboration of the industrial cluster. Tao Chun ${ }^{[26]}$ pointed that the government should provide the external environment adapting for the synergy innovation. The policy support from the government is the important driving force to push the synergy innovation. The intermediary service organizations are the nodes connecting the innovative agents, the bridges and ties for knowledge flow and technology transfer between the enterprise and the market.

Zhou Zheng ${ }^{[25]}$ thought the driving elements outside of the enterprises, the universities and the research institutes alliance is the external driving force to the synergy innovation mostly covering the technology pushing force, the marketing demand pulling force, the marketing competition pressure and the government supporting force. $\mathrm{Xu}$ Jing ${ }^{[19]}$ considers the motion factors covering the benefit driving, the technology pushing, the market oriented, the technology potential disparity, the capital support and the environment driving power. Tao Chun ${ }^{[26]}$ puts forward the knowledge difference causing the knowledge transfer in the enterprises, the universities and the research institutes alliance. The benefit complementary between the university and the enterprise constructs the social driving power foundation and only the synergism between the knowledge potential disparity and the benefit complementary can result in the knowledge transfer in the enterprises, the universities and the research institutes alliance.

\subsection{Classification on the Driving Force Sources}

The major partners in the synergy innovation are the industries, the universities and the research institutes and the ancillary partners are the government, financial organizations, science and technology service agents form the technology innovation chain and synergy innovation network through the scientific research, the marketing development, the capital, the policy and the information support. The technology pushing force covers new technology mindset inducement, the technology channel, the technology anticipation, the input pushing. The government is the initial pusher in the synergy innovation among the industries, the universities and the research institutes. The government supports the synergy innovation among the industries, the universities and the research institutes on the behavior guidance and the policy motivation. The influencing factors and the pushing mechanism in the knowledge transfer among the industries, the universities and the research institutes put forward the knowledge differentiation with the specific characteristics on the knowledge quantity, quality and structure. There exists the absolute knowledge disparity. The knowledge disparity between the university and the enterprise is the nature driving force to the knowledge transfer among the industries, universities and the research institutes alliance.

\subsection{Classification on the Driving Force Attributes}

The innovation driving forces can be classified into the pushing power, the pulling power and the hindering power according to the outcome attributes of the enterprise innovation activity from the synergy innovation driving forces' influence. The pulling forces for the enterprises to construct the synergy innovation include the government policy guidance, the administrative protection, the capital support from the financial organizations, the information bridge from the intermediary agents and the knowledge transfer from the universities. The pushing forces cover the enterprise pursuits of the excess profit, the entrepreneur spirit reflection, the enterprise culture nurturing and the organization motivation ${ }^{[27]}$.

Every coin has two sides to all the type of elements influencing the synergy innovation driving forces. These elements might have the positive or negative influence to the innovation driving forces as the driving force to the enterprise innovation or the boosting forces to the enterprise innovation. When one driving force is too strong, it can influence the development of the other driving element and then change into the hindering elements.

\subsection{Relationship between Internal and External Driving Forces}

Innovation is one interactive process. The enterprises seldom rely on the knowledge and resource on their own to realize the innovation singly. All the major partners can work on the innovation of the value chain segments through cooperation to achieve the labor specialization, cooperate on the industrial investment, set up the research \& development center, explore the external market and share the synergy achievements. This can 
conquer the restriction on the innovation with the complementation on the capital, the technology, the resource, the talent and the brand.

There're close and complicated synergy connection and coherence effects among the external enterprise driving forces on innovation. The internal innovation driving forces also have complicated non-linear effects and connections. There're strong non-linear coupling influence on the external and internal innovation driving forces. The external driving mechanism can enhance the development of the enterprise synergy innovation and the internal driving mechanism can support the improvement of the enterprise innovation mechanism. With the development of the globalization, it's very important to strengthen the interaction of the enterprise internal and external networking to achieve the resource, technology, information and knowledge outside of the network. It can also help acquiring the external information and resource through the internal and external networking interaction in the cluster to maintain the openness and dissipation of the cluster and is good to renew the cluster knowledge avoiding the cluster fossilization and locking.

\section{Successful Synergetic Innovation Experience from the Developed Country}

\subsection{Japan: Dominating Enterprises take the core organizing role}

In Japan, most of the synergy innovation are dominated by the big enterprise as the dominating enterprise forming the technology research combination. The dominating enterprise organize the enterprise-enterprise synergy innovation networking with the suppliers, purchasers, competitors and cooperators. The interactive cooperation between the enterprise and the business customer, supply chain enterprise and competitive enterprise can enhance the innovation spillover through the value-added process. The dominating enterprise in the innovation network is responsible for the division of labor cooperation and each performs one's own functions to carry out the new technology research and development in the synergy innovation. All the technologies can't exist singly and their development need the support from the external supporting system. We call the dominating enterprises order parameters and the supporting enterprises external parameters. The quality of the technology product from the external parameters' enterprise can influence the product quality of the order parameters' enterprise. The technology improvement depends mostly on the external parameters' enterprise action to form the interactive symbiosis. The external parameters' enterprise is the important information resource to the dominating enterprise's product development and improvement. The cooperation between the order parameters' enterprise and the external parameters' enterprise can strengthen the enterprise's operation flexibility and marketing adaption, at the same time lower the enterprise operation risk and facilitate the product development and innovation frequency ${ }^{[28]}$.

It is more beneficial for the enterprises to develop the core competency and technology resource through the knowledge and technology cooperation between different enterprises achieving the synergy effects. The informal agreements and the formal long term strategic alliance can enhance the gradual innovation in the enterprise. In Japan manufacturing industry, there're stable vertical division and cooperation among the large, medium and small enterprises. The enterprises form the stable mutual trust during the long term trade, and the connection help the order parameters' enterprises provide the adequate innovation incentives to the external parameters' enterprises, and enhance the synergy innovation among the enterprises. There's one mechanism in the Japan manufacturing industry, the order parameters' enterprises are required to define the price reduction and the price reduction period clearly. They don't change according to the productivity of the external parameters' enterprises improve or not. This mechanism can undoubtedly improve the external parameters' enterprises innovation competency and the external parameters' enterprises can gain the benefit from the productivity improvement $100 \%$. The order parameters' enterprises can improve the innovation competency through the cooperation with the suppliers, and then improve the competitive strength.

\subsection{Europe Union: Government Push, Industry Association play mediating effect}

It is crucial for the government to push the synergy innovation to the important technical projects. Europe Union actively push forward the forming of the "Government-Enterprise-Intermediary agent" synergy innovation network. For example, there're Europe Union R\&D framework plan, Eureka plan, Galileo plan and Airbus plan, etc. that are the synergy innovation promoted by Europe Union and multiple Governments. Europe Union construct the public information sharing service platform to support the enterprises to participate in the important technical projects. Under the macroscopic coordination of Europe Union, Europe Union combine the 23 member states and other 300+ partners as Norway, Switzerland, Turkey and China, implement the associated development strategy and form the knowledge alliance on the synergy innovation and provide the free consulting service to all the Europe innovation members and also provide the free information service to the industrial innovation stakeholders. 
The Europe industrial associations play important roles in supporting the important projects' synergy innovation. They establish intermediary agents with other governments to form the crisscrossing nodes in the innovation network. The intermediary service organizations can provide the comprehensive service as the bridge and tie for the knowledge flow and technology transfer between the enterprise and the market. The industrial association is very important to play intermediary role in the German enterprises' synergy innovation. The enterprise is required to participate in at least one industrial association regulated in the German law. The association play strong intermediary role to enhance the synergy innovation among the association members. It is mentioned that the industrial associations can play 6 major functions as information exchange, communication cohesiveness, consulting service, knowledge integration, incubation and commercialization. The German industrial associations complement the resource and capability scarcity of the medium and small enterprises' innovation and support these enterprises can keep up with the rapidly changing science \& technology and market and also help the enterprise renew the networking connections. The industrial associations emphasize the role of the industrial associations, put forward the innovation policy, influence and canvass the government to provide assisting funds to the industrial associations in the synergy innovation ${ }^{[29]}$.

\subsection{U.S: Government guide Enterprise to play self-organizing in the market}

U.S advocates the free competitive marketing economy. The competition between the enterprises is totally free. The innovation is forming through self-organizations' cooperation and collaboration into "Enterprise-Market-Research organization" synergy innovation mode gradually.

It's through the marketing mechanism to mobilize the synergy innovation between the government, research institutes and the enterprises. Especially under the circumstance of capital scarcity in the financial crisis, the cooperation happens frequently between research institutes and the industry and the enterprises with the government guidance and marketing promotion ${ }^{[30]}$.

The research organizations cover the universities, the research institutes, the colleges and are the carriers for the knowledge creation, the technology production and talents cultivation and the most important innovation source in the enterprises' synergy innovation network. The innovation networking from the cooperation between the enterprises, the universities and the research institutes can lower the trading cost and the networking cooperation risk. It's one effective way to achieve the innovation. The enterprises rely on the market, cooperate and communicate with the research institutes on the frequent, equal and informal basis to enhance the quick flow of the innovation elements and set the keynote for the synergy innovation.

The U.S government constructs the successful guiding mode and acquires successful synergy innovation between two territories as the synergy innovation between the military technology and the civilian technology, the synergy innovation between the universities and the enterprises. The innovation strategy in U.S requires the basic science theory research to be leading in the world and the basic science research is with the universities playing the core roles. U.S government also pushes the achievements from the basic science research into commercialization and industrialization.

\section{Results}

The ultimate goal of the synergy innovation is to develop win-win cooperative mechanism between the enterprises, research institutes and universities, financial structures, intermediary organizations, upstream and downstream enterprises. We think that the forming of the synergy innovation not only need the higher level cooperation between the enterprise, university and research institute, but also the inputs of other elements as the information linking from the intermediary agents and government policy supporting through the study on the internal and external driving forces to the synergy forces. The driving forces on synergy innovation covers the enterprises' pursuits to revenue and the recognition on the enterprises' sustainable development. We believe that the enterprises can get the substantial development when establishing synergy innovation.

\subsection{Supporting to Synergy Innovation Should meet Synergy Innovation requirements}

Synergy Innovation can't rush headlong into action and should be supported when meeting the requirements actually. The major conditions for the mega projects of the synergy innovation are with big science character and crossing disciplines. Single enterprise can't complete such tasks. The conditions of the synergy innovation mainly include strong interactive technology, resource integration, management complexity, tremendous investment, high risk. The synergy innovation effect is more obvious as the technology relevancy gets stronger. The synergy innovation also covers the innovation organization, innovation infrastructure, innovation resource and innovation environment. These four elements are interactive. The innovation organization mainly includes the enterprise, research institute, incubator and intermediary agent. The innovation infrastructure can cover the 
information network, library, database, public infrastructure. The innovation resources are capital, talent, information, knowledge and patent, etc. The innovation environment can include the policy and law, management system, the general name of the market and service.

Not every elements is the same important to the innovation for the enterprise. The importance of the synergy is different to every enterprises. The most successful companies are those that can set up one strategic topic according to their own characters, and then choose the correct core elements and the synergy combination. One synergy oriented company needs the synergy with higher requirements between R \& D, manufacturing and marketing department.

\subsection{Government Role to Support Enterprises Realize Self-organization in the Market}

The essential conditions to the self-organization are that the system should be the open system, away from equilibrium state and have the dynamic mechanism with the non-linear feedback. There exists mutual competition and cooperation between the enterprises in the self-organizations. These enterprises cooperate together and take hand in hand action orderly to achieve the specific objective.

The enterprises compete freely in the market is to achieve the safety and the stability through the cooperation and the risk mitigation is to actual driving force for the enterprise synergy innovation. The government's function is mainly to protect and guide the direction of the innovation from the perspectives of the system, the environment and the policy through the law, the economy and the organization management to stimulate the synergy innovation between the universities and the enterprises, protect the outcome of the innovation and coordinate the contradiction among the innovation main partners. The synergy innovation combines the enterprise position, the implementation ability, the marketing opportunity and the threat.

It's crucial in the synergy innovation to recreate the new knowledge and new product. It's important to guarantee the synergy innovation with developing effective intellectual property management and specify the property attribution clearly.

\subsection{Industry Association, Industrial Alliance and Dominating Enterprises Play Core Role in the Synergy Innovation}

Once core power is needed to lead and realize the enterprise synergy innovation. This power can guarantee the holistic and systematic of the synergy innovation. Different countries apply the synergy innovation strategy with different focuses on the basis of their traditional history and realistic predicament. Whatever the enterprise, the industrial association, the industrial alliance, the government or the marketing power as the core element to the synergy innovation, the government should provide good environment and the market can provides the basic agent position to the enterprise. They're the pre-conditions to the synergy innovation. It is more realistic to follow the actual demand of the innovation and the industrial association, the industrial alliance and the enterprise can take the core role to the enterprise synergy innovation respectively.

Europe Union and U.S encourage the industrial association and the industrial alliance to lead the enterprise synergy innovation. Japan enterprises make the imitation and system innovation to enhance the synergy innovation upgrading the holistic technology. This approach can help implement with the holistic mode from the beginning, form the whole innovation linking all the innovation technology and establish the new industry enhancing the technology innovation and industrial upgrades in the short term.

\section{Reference}

Alexander, L., \& Knippenberg, D. V. (2014). Teams in pursuit of radical innovation: A goal orientation perspective. Academy of Management Review, 39(4), 423-438. https://doi.org/10.5465/amr.2012.0044

Alexy, O., Bascavusoglu-Moreau, E., \& Salter, A. J. (2016). Toward an aspiration-level theory of open innovation. Industrial and Corporate Change, 25(2), 289-306. https://doi.org/10.1093/icc/dtw003

BAI, J. H., CHEN, Y. H., \& LI, J. (2008). Innovation synergy and its influential factors inside enterprise. Studies in Science of Science, 2, 32.

Brunswicker, S., \& Vanhaverbeke, W. (2015). Open innovation in small and medium sized enterprises (SMEs): External knowledge sourcing strategies and internal organizational facilitators. Journal of Small Business Management, 53(4), 1241-1263. https://doi.org/10.1111/jsbm.12120

Carnabuci, G., \& Operti, E. (2013). Where do firms' recombinant capabilities come from? Intraorganizational networks, knowledge, and firms' ability to innovate through technological recombination. Strategic Management Journal, 34(13), 1591-1613. https://doi.org/10.1002/smj.2084 
Cheng, B. (2014). The Connotation, Ingredient and Functional Localization of the Synergy Innovation among the Government, the Enterprise and the University. Science and Technology Innovation and Production, (1), $1-4$.

Cheng, J. (2012). The Best Innovation Enterprise. Beijing: Scientific Publishing.

Chesbrough, H., \& Chen, E. L. (2015). Using Inside-Out Open Innovation to Recover Abandoned Pharmaceutical Compounds. Journal of Innovation Management, 3(2), 21-32.

Eesley, C. E., Hsu, D. H., \& Roberts, E. B. (2014). The continent effects of top management teams on venture performance: Aligning founding team composition with innovation strategy and commercialization environment. Strategic Management Journal, 35(12), 1798-1817. https://doi.org/10.1002/smj.2183

Fan, T. (2008). Synergy Innovation Mechanism Research on the Innovation Networking of the Industrial Cluster. Forum on Science and Technology in China, (7), 26-30.

Gloor, P. A. (2005). Swarm creativity: Competitive advantage through collaborative innovation network. New York: Oxford University Press.

Guang, C. (2005). Benchmarking and Audit of Enterprise Synergy Innovation Management. Chinese Journal of Management, 3, 014.

Hochleitner, F. P., Arbussà, A., \& Coenders, G. (2016). Inbound open innovation in SMEs: indicators, non-financial outcomes and entry-timing. Technology Analysis \& Strategic Management, 1-15. https://doi.org/10.1080/09537325.2016.1211264

Hodson, R. (2016). Open innovation. Nature, 533(7602), S53-S53. https://doi.org/10.1038/533S53a

Ketchen, D., Ireland, R., \& Snow, C. (2007). Strategic entrepreneurship, collaborative innovation, and wealth, creation. Strategic Entrepreneurship Journal, 1, 371-385. https://doi.org/10.1002/sej.20

Lawson, B, \& Samson, D. (2001). Developing innovation capability in organizations: a dynamic capabilities approach. International Journal of Innovation Management, 5(3), 377-400. https://doi.org/10.1142/S1363919601000427

Li, B., \& Dong, Y. (2009). The Construction of the Enterprise Original Driving Forces' System based on the Synergetics. Science of Science and Management of S.\&.T., (1), 56-60.

Li, D. (2013). The Government Investing Project base on the Synergy Theory Tracking and Auditing Mode. System Engineering Theory and Practice, 33(2), 405-413.

Love, J. H., Roper, S., \& Vahter, P. (2014). Learning from openness: The dynamics of breadth in external innovation linkages. Strategic Management Journal, 35(11), 1703-1716. https://doi.org/10.1002/smj.2170

Luo, T., \& Yu, C. (2009). Technology System Innovation Strategy in Japan. Science and Technology Progress and Policy, (9), 155-156.

Naqshbandi, M. M, Kaur, S, \& Ma, P. (2015). What organizational culture types enable and retard open innovation? Quality \& Quantity, 49(5), 2123-2144. https://doi.org/10.1007/s11135-014-0097-5

Naqshbandi, M. M. (2016). Managerial ties and open innovation: examining the role of absorptive capacity. Management Decision, 54(9), 2256-2276. https://doi.org/10.1108/MD-03-2016-0161

Naqshbandi, M., \& Kaur, S. (2014). Do managerial ties support or stifle open innovation? Industrial Management \& Data Systems, 114(4), 652-675. https://doi.org/10.1108/IMDS-10-2013-0407

Naqshbandi, M. M., \& Kaur, S. (2011). A study of organizational citizenship behaviors, organizational structures and open innovation. International Journal of Business and Social Science, 2(6), 182-193.

Persaud, A. (2005). Enhancing synergistic innovative capability in multinational corporations: An empirical investigation. Journal of Product Innovation Management, 22(5), 412-429. https://doi.org/10.1111/j.1540-5885.2005.00138.x

Peter, K., Sabine, M., Frances, J., et al. (2011). Innovation and network collaboration: An HRM perspective. International Journal of Technology Management, 56(2/3/4), 138-153.

Saebi, T., \& Foss, N. J. (2015). Business models for open innovation: Matching heterogeneous open innovation strategies with business model dimensions. European Management Journal, 33(3), 201-213. https://doi.org/10.1016/j.emj.2014.11.002

Schumpeter, J. (1999). Capitalism, Socialism and Democracy (pp. 11-15). Wu Liangjian,Translator. Beijing: The 
Commercial Press.

Serrano, V., \& Fischer, T. (2007). Collaborative innovation in ubiquitous systems. International manufacturing, 18(5), 599-615. https://doi.org/10.1007/s10845-007-0064-2

Shao, Y. (2016). Regional Technology Innovation Capability forming Mechanism Analysis. Journal of Management Sciences in China, 9(4), 1-10.

Shin, S. J., Kim, T. Y., Lee, J. Y. et al. (2012). Cognitive team diversity and individual team member creativity: A cross-level interaction. Academy of Management Journal, 55(1), 197-212. https://doi.org/10.5465/amj.2010.0270

Singh, SKG., Naqshbandi, M. M., \& Jayasingam, S. (2014). Open Innovation in SMEs: Drivers and Inhibitors. Asia-Pacific Tech Monitor, 31(2), 20-24.

Stefan, S. (2009). Infome diaries and collaborative innovation: A case study on Information and Technology centered Intermediation in the Dutch Employment and Social centered Intermediation in the Dutch Employment and Social Security Sector. Information Policy, 14(4), 245-262.

Tao, C. (2013). Realizing Route on the Enterprise Synergy Innovation. Forum on Science and Technology in China, 1(9), 20-24.

Weigelt, C., \& Miller, D. J. (2013). Implications of internal organization structure for firm boundaries. Strategic Management Journal, 34(12), 1411-1434. https://doi.org/10.1002/smj.2074

$\mathrm{Wu}$, X. (2012). U.S Synergy Innovation Alliance on the Enterprise, University and Research Institute Construction and Experience. China Higher Education Research, (4), 47-50.

Xiang, G., \& Wang, Y. (2004). Enterprise Sustainable Innovation Driving Forces' Mechanism Research. Science Research and Development Management, 25(6), 108-114.

$\mathrm{Xu}, \mathrm{F}$., \& Xu, R. (2011). Foreign Government supporting to Key Science \& Technology Plan or Specific Organization Management Character Analysis and Reference. Science and Technology Management Research, (14), 37-40.

Xu, J. (2012). The Driving Forces of the Cooperation Mechanism Study among the Enterprise, the University and the Research Institutes in China. Forum on Science and Technology in China, (7), 74-80.

Yang, L. (2011). The Internal Influencing Factors Study on the Synergy Innovation of the Supply Chain Enterprise. Enterprise Logistics, (15), 55-56.

Zhang, W. (2003). Technology Route Creation based on the Enterprise Innovation Networking. Studies in Science of Science, 21(6), 657-661.

Zhang, Z. (2013). The Synergy Innovation among the Enterprise, University and Research Institute Mechanism Research with the Government's Guidance. Dalian: Dalian University of the Technology and Engineering.

ZHENG, G., ZHU, L., \& JIN, J. (2008). Innovation by Total Synergy: A Five-stage Model-A Case Study on Haier Group. Journal of Industrial Engineering and Engineering Management, 2, 6.

Zhou, Z. (2013). The Driving Forces' Mechanism Study on the Enterprise, the University and the Research Institute Synergy Innovation in China. Soft Science, 27(7), 52-56.

\section{Copyrights}

Copyright for this article is retained by the author(s), with first publication rights granted to the journal.

This is an open-access article distributed under the terms and conditions of the Creative Commons Attribution license (http://creativecommons.org/licenses/by/4.0/). 